\title{
Right Ventricular Hypertrophy by ECG Finding
}

National Cancer Institute

\section{Source}

National Cancer Institute. Right Ventricular Hypertrophy by ECG Finding. NCI Thesaurus.

Code C71077.

An electrocardiographic finding suggestive of a hypertrophied right ventricle,

characterized by large $\mathrm{R}$ wave amplitudes in the right precordial leads and secondary

findings of right atrial enlargement, right axis deviation, and typical pattern of ST

depression and T wave inversion in the right precordial leads. (CDISC) 